\title{
Diversity of Plastid Types and Their Interconversions
}

\author{
Heebak Choit, Taegyu Yit and Sun-Hwa Ha* \\ Department of Genetics and Biotechnology, Graduate School of Biotechnology, College of Life Sciences, Kyung Hee \\ University, Yongin, South Korea
}

OPEN ACCESS

Edited by:

Peter Julian Nixon,

Imperial College London,

United Kingdom

Reviewed by:

Enrique Lopez-Juez,

Royal Holloway, University of London,

United Kingdom

Niaz Ahmad,

National Institute for Biotechnology and Genetic Engineering, Pakistan

Fei Zhou,

Huazhong Agricultural University,

China

*Correspondence:

Sun-Hwa Ha

sunhwa@khu.ac.kr

†These authors have contributed

equally to this work

Specialty section:

This article was submitted to

Plant Cell Biology,

a section of the journal

Frontiers in Plant Science

Received: 07 April 2021

Accepted: 24 May 2021

Published: 17 June 2021

Citation:

Choi H, Yi T and Ha S-H (2021) Diversity of Plastid Types and Their

Interconversions.

Front. Plant Sci. 12:692024.

doi: 10.3389/fp/s.2021.692024
Plastids are pivotal subcellular organelles that have evolved to perform specialized functions in plant cells, including photosynthesis and the production and storage of metabolites. They come in a variety of forms with different characteristics, enabling them to function in a diverse array of organ/tissue/cell-specific developmental processes and with a variety of environmental signals. Here, we have comprehensively reviewed the distinctive roles of plastids and their transition statuses, according to their features. Furthermore, the most recent understanding of their regulatory mechanisms is highlighted at both transcriptional and post-translational levels, with a focus on the greening and non-greening phenotypes.

Keywords: chloroplast, chromoplast, de-greening, etioplast, greening, leucoplast, non-greening

\section{INTRODUCTION}

Plastids first developed during an endosymbiotic event between photosynthetic prokaryotes and the eukaryotic ancestors of algae. During the subsequent co-evolution of the engulfed plastid and eukaryote cells there were extreme changes in the functions of the plastids, including the development of regulatory networks (Keeling, 2013; Ševćíková et al., 2015). Although plastids are common subcellular organelles in plants, previous research has been a bias toward the photosynthetic plastids called chloroplasts or carotenoid enriched plastids called chromoplasts (Cruz et al., 2018; Pinard and Mizrachi, 2018). Moreover, recent studies on the regulatory pathways of plastids have mainly focused on light switching and hormonal treatments (López-Juez, 2007; Larkin and Ruckle, 2008; Larkin, 2014; Al-Babili and Bouwmeester, 2015; Liu et al., 2017).

In this review, the distinctive features for each plastid type are briefly described to help understand the general properties of plastids. A point of interest is that new plastids cannot be generated or born, and are duplicated or transited from other plastids. This indicates that the interconversion of plastids is important, and this is consequently addressed in this review. However, as plastid interconversions are tissue- and species-specific events, representative research was carefully selected and summarized.

Although there are many cases of plastid interconversions, the molecular mechanisms in the signaling networks of chloroplasts and chromoplasts were the focus of this review. During chloroplast development, different wavelengths of light synergistically trigger transcriptional regulators by releasing the post-translational inhibition of $\mathrm{E} 3$ ligase complexes. This leads to an increase in transcriptional regulators which induce photomorphogenic enzymes and chloroplast development. Chromoplasts are differentiated by the induction of carotenoid biosynthesis genes through the induction of transcriptional regulators. In this review, the chloroplast and chromoplast molecular networks are described with newly discovered regulators at both transcriptional and post-translational levels. Together with general examples of plastid interconversion, the overview of 
gene-specific molecular networks and their participating genes will strongly support work toward genetic improvement of multiple traits which related to plastid interconversion.

\section{PLASTID TYPES AND ROLES}

Plastids can be divided into several types based on their color, morphology, and ultrastructure (Whatley, 1978; Møller, 2006; Wise, 2007). The characteristics of each plastid type are tightly related to their specific roles (Figure 1). Undifferentiated plastids are called "proplastids" and are mainly found in meristematic and reproductive tissues, and they are identified as being small and having clear ultrastructures. They can be differentiated into "leucoplasts" in white, "chloroplasts" in green, and "chromoplasts" in either yellow, orange or red. Intermediate forms of chloroplasts are called "etioplasts" and senescent forms of chloroplasts are called "gerontoplasts". Leucoplasts are categorized by their lack of color, but can be further separated according to their biochemical characteristics based on their contents, such as starch enriched "amyloplasts", protein enriched "proteinoplasts", and lipid enriched "elaioplasts" (Lopez-Juez and Pyke, 2004; Jarvis and López-Juez, 2013).

\section{Proplastids}

Proplastids are undifferentiated plastids that maintain a minimal plastid structure. So that, their organelle transmission can take place between generations. They are colorless and tiny in size when compared to the other types of plastid with no significant morphological characteristics (Jarvis and López-Juez, 2013; Liebers et al., 2017). They are mostly found in meristematic and egg cells of plants and sometimes during pollen formation in specific species such as Pelagonium and barley (Hordeum vulgare) (Hagemann, 2004; Sakamoto et al., 2008; Gajecka et al., 2020). Also, the nodule proplastids in root tissues have been reported to play a vital role in the biochemistry of nitrogen fixation in the legume family (Boland and Schubert, 1983; Ferguson, 1998; Greco et al., 2012).

\section{Chloroplasts}

Chloroplasts are one of the most well-studied types of plastid and are found in all photosynthetic organisms (Waters and Langdale, 2009; Rottet et al., 2015). They can turn light energy into chemical energy via photosynthetic protein complexes. In chloroplasts, multiple stacks of disk-like single lipid layers called thylakoids form grana and these create large lipid surface layers which anchor the photosynthetic protein complexes. The edges of the disk-like thylakoids also form unique hydrophobic pocket structures called plastoglobules, which help to enlarge the internal area of the lipid bilayer (Rottet et al., 2015). Plastoglobules are identified as sites of carotenoid breakdown for apocarotenoid production (Rottet et al., 2016) and for non-endogenous carotenoid accumulation (Mortimer et al., 2017).

The green color of chloroplasts is due to chlorophyll which is core component for photosynthesis, but the chloroplasts also have an abundance of multiple hydrophobic terpenes, such as lutein, $\beta$-carotene, violaxanthin, and neoxanthin, which also help to support photosynthesis (Ruiz-Sola and RodríguezConcepción, 2012). Not only converting the UV-blue range of light to the electro energy for photosynthesis (Dall'Osto et al., 2014), the carotenoid in chloroplast also play a major role in photoprotection by modulating the non-radiative dissipation of excess excitation energy (Niyogi, 2000; Dall'Osto et al., 2005). Specially, hydroxylated carotenoids referred to as xanthophylls support photoprotection by mediating direct quenching of chlorophyll $(\mathrm{Chl})$ triplets $\left({ }^{3} \mathrm{Chl}^{*}\right)$ or by scavenging the reactive oxygen species (ROS) generated during photosynthesis (Niyogi et al., 1997; Havaux and Niyogi, 1999; Dall'Osto et al., 2007). Consequently, the balance between photosynthesis, photoprotection, and ROS scavenging is an important function in chloroplasts. Starch granules, protein bodies, and lipid bodies are often formed in chloroplasts for temporal storage and to help meet the demands of developmental and environmental cues.

\section{Etioplasts}

Etioplasts are specialized intermediate plastid types that are mostly found in dark grown seedlings. In natural conditions, they are easily found in seedlings that grow under the soil. They are the transient state of development for chloroplasts and are also considered as a status of austerity because they stop the development of photosynthetic chemicals and structures which are unnecessary in the dark. Within etioplasts, in general, single well-arranged paracrystalline prolamellar body and tubular prothylakoids are formed, and these are interspersed with numerous small plastoglobule with high amounts of carotenoids; mainly lutein and violaxanthin which help to increase the transition to chloroplasts (Park et al., 2002; Rodríguez-Villalón et al., 2009; Solymosi and Schoefs, 2010; Pipitone et al., 2021).

\section{Leucoplasts and Derivatives}

Leucoplast are characterized by their white structures (Carde, 1984). They are often found in non-photosynthetic tissues that have storage functions. However, advances in microscopy technology and an increase in detection strategies have made it possible to classify leucoplast in more detail. Except for undeveloped proplastids, three types of white plastids, amyloplasts, proteinoplasts, and elaioplasts, are further characterized as sub-types of leucoplasts (Howitt and Pogson, 2006; Sadali et al., 2019).

\section{Amyloplasts}

Amyloplasts are characterized by starch granules that store high density starch. During the formation of amyloplast membranes, various lipids such as free fatty acids, lysophospholipids, lysophosphatidylcholine, and lysophosphatidylethanolamine are also included in the starch granules (Gayral et al., 2019). Amyloplasts are commonly found in sink tissues including seeds, fruits, tubers, and roots for carbon storage, but they are also often found at low frequencies, in various tissues including leaves, stems, and roots for temporal storage (Jarvis and López-Juez, 2013). It is interesting that the amyloplasts is not stable in some cases, for example in Arabidopsis leaves, the accumulation and 


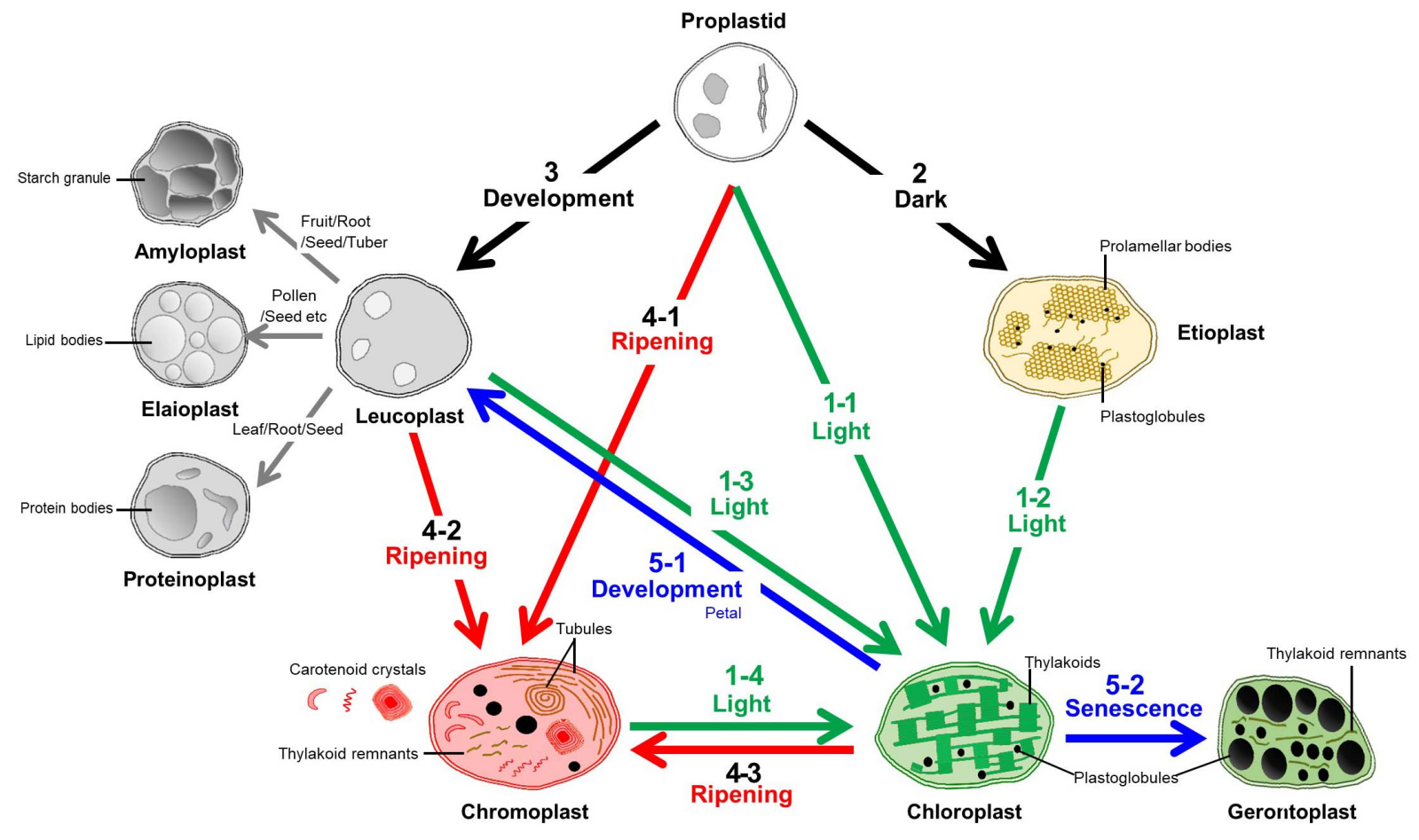

FIGURE 1 | Transition pathways among various plastids. The characteristics and plastid interconversion pathways of the plastids were classified according the color and number of the arrow. The transition to a chloroplast is called "Greening" and identified with the number "1". This is mainly triggered by light signals from proplastids, etioplasts, leucoplasts, and chromoplasts. Etioplasts can develop from proplastids in dark conditions and this identified by the number "2". The number " 3 " indicates leucoplast development that is triggered by diverse development processes to generate starch, lipid, and protein enriched sub-types called amyloplasts, elaioplasts, and proteinoplasts, respectively. Mainly during the ripening stage, diverse types of the carotenoid crystals were generated within the plastids called chromoplasts from the proplastids, leucoplasts, and chloroplasts and this is identified with the number "4". Together with etioplast and leucoplast development (2,3), chromoplast development (4) was identified as a "Non-greening" plastid transition. The loss of green color from the chloroplasts is called "De-greening" and identified with the number " 5 ", and these chloroplasts are then transited into leucoplast or gerontoplast by developmental regulation or during senescence, respectively.

the loss of starch are highly dynamic, following a daily cycle due to photosynthetic activity or its absence (Fernandez et al., 2017). Unlike other types of plastid, amyloplasts often coexist with different types of plastid in the same cell. However, in the tissues of species, such as the winter squash, peach palm fruit, and sweet potato tuber (Jeffery et al., 2012; Hempel et al., 2014; Zhang et al., 2014), combinatory types of plastid called amylochromoplasts were observed which stored starch granules with carotenoid crystals in the same plastid. Starch granules are also found inside different types of plastids such as chloroplasts. As well as their storage functions, the amyloplast from Arabidopsis roots were reported to contribute to gravitropism signaling (Chen et al., 1999; Nakamura et al., 2019).

\section{Elaioplast}

Elaioplasts are characterized by ultrastructures filled with hydrophobic contents such as lipids and terpenoids. They are specialized for biosynthesis and the storage of lipids, but also have diverse functions in specific tissues. In citrus fruits, elaioplasts are exported into secretory pockets and they can have large impacts on aroma and taste (Zhu et al., 2018). In pollen, exine formation was found to be highly dependent on elaioplasts (Quilichini et al., 2014).

\section{Proteinoplasts}

In specific cases, protein bodies can be found in plastid structures, generally in the cytosolic area, and these are called proteinoplasts (or proteoplast, aleuroplast, aleuronaplast; Dashek and Miglani, 2017). Proteinoplasts are generally found in many different types of cell at several different stages of plastid development (Thomson and Whatley, 1980). Due to the location and contents of proteinoplasts, they are thought to have a role in protein storage. Furthermore, the proteinoplasts of tobacco root showed strong oxidase activity which may convey a specific function (Vigil and Ruddat, 1985).

\section{Chromoplasts}

Chromoplasts have colorful characteristics as they accumulate large amounts of carotenoids and their specific colors are determined by specific types of carotenoids. During chromoplast development, the concentrated carotenoids which form globular, round, coiled shaped carotenoid crystals at the mature stage are produced and stored in hydrophobic structures called plastoglobules (Schweiggert et al., 2011). The plastoglobules are lipoprotein particles attached to thylakoids through a half-lipid bilayer and function in both lipid biosynthesis, storage and cleavage (Austin et al., 2006; Rottet et al., 2016). These colored 
plastids with highly developed plastoglobules are used to attract pollinators and seed disseminators in reproductive tissues or for the storage of carotenoids and hydrophobic metabolites (Rottet et al., 2015).

\section{Gerontoplasts}

Gerontoplasts are chloroplast-derived plastids adjusted for recycling of plastid which are mainly found during senescence processes or under stress condition (Biswal et al., 2012). As the chloroplast possess up to $80 \%$ of the leaf nitrogen pool, degradation of chloroplasts and the recycling of their nutrients is important for plant survival (Makino and Osmond, 1991). And the degradation of chloroplast proteins has been reported for three different pathways, autophagy, Senescence Associated Vacuoles (SAV) and Chloroplast Vesiculation (CV) (Ishida et al., 2008; Xie et al., 2015). When the senescence process starts, plastids undergo serial changes in their ultrastructures. It is difficult to define the characteristics of gerontoplasts at the beginning of senescence, but there are a few specific characteristics that have been identified (Biswal et al., 2012). First, gerontoplasts do not contain starch granules, probably because they are unable to continue photosynthesis which replenish the starch daily. Second, their thylakoid structures and chlorophyll have also been degraded. Third, the size of their plastoglobules is enlarged and their numbers increased, probably due to the accumulation of lipophilic substances from degraded lipid structures and hydrophobic contents.

\section{Specialized Types: Desiccoplasts, Phenyloplasts, and Xyloplasts}

Desiccoplasts are plastids that can be interconverted between chloroplasts and proplastids in desiccation tolerant plants (Solymosi et al., 2013). Phenyloplasts are phenol enriched colorful plastids identified as a new plastid type when compared to chromoplasts because of their different storage contents and the homeostatic roles of phenols (Brillouet et al., 2014). Xyloplasts are specialized plastids in secondary vascular tissues that are dedicated to the synthesis of precursors for monolignol production, derived from either proplastids, or more likely, amyloplasts (Pinard and Mizrachi, 2018).

\section{PLASTID TRANSITIONS}

\section{Development of Chloroplast: Greening Phenotype \\ From Proplastids}

Transitions of proplastids to chloroplasts mainly occur in the shoot apical meristem and during embryogenesis (Table 1). According to Arabidopsis research, the process of differentiation starts with the shoot apical meristem of the young leaf and continues into leaf development. The differentiation process occurs in the upper layer and central subtending cell layers, and is not affected by the intensity of light, but a light period of 5$10 \mathrm{~h}$ is required (Yadav et al., 2019). By observing embryonic development in Arabidopsis, chloroplast-containing cells were identified at the globular stage of embryogenesis, indicating the development of chloroplasts from undifferentiated proplastids (Tejos et al., 2010). In in vitro experiments, dark grown calluses only had proplastids while those grown in the light had short thylakoids and chloroplasts containing an immature membrane structure (Ladygin et al., 2008).

\section{From Etioplasts}

When etioplasts are exposed to light, protochlorophyllide, the chlorophyll precursor of prolamellar bodies, is immediately converted to chlorophyllide by light-dependent NADPH:Pchlide oxidoreductase. Following this, chlorophyllide is converted to chlorophyll through enzymatic processes (Fujii et al., 2019). It occurs mainly in plant leaf tissues and can be easily found in the plant world, for example, the inner leaves of white cabbage (Brassica oleracea "Capitata"), lettuce (Lactuca sativa) and cucumber cotyledons (Cucumis sativus) (Solymosi et al., 2004; Kanamoto et al., 2006; SobieszczukNowicka et al., 2007). De-etiolation studies using tobacco leaves reported that the physical structures of the etioplast prolamellar bodies changed almost immediately when exposed to light, and regularity and size reductions occurred (Armarego-Marriott et al., 2019). Recent work well described in Arabidopsis revealed the chloroplast biogenesis from etioplast into two distinct phases: the "Structure Establishment Phase" for disassembly of the prolamellar body, gradual formation of the thylakoid membrane and initial increase of galactolipids and photosynthesis-related proteins and the "Chloroplast Proliferation Phase" for cell expansion, a linear increase of prokaryotic and eukaryotic galactolipids, photosynthesis-related proteins and increased grana stacking (Pipitone et al., 2021).

\section{From Leucoplast}

Non-photosynthetic leucoplasts can be converted to photosynthetic chloroplasts. In the cortical parenchyma tissues of potato tubers, directly beneath the periderm, amyloplasts (starch enriched leucoplast) are converted to chloroplasts by the accumulation of chlorophylls under light sources (Tanios et al., 2018). In addition, the needle leaf of Norway spruce (Picea abies) also showed the plastid transitions according to growth and seasonal changes. In Norway spruce, amyloplasts for nutrient accumulation and chloroplasts for photosynthesis are generated at the seedling stage. Seasonally, amyloplasts appear mainly due to the accumulation of large amounts of starch in the autumn and winter and are converted back to typical chloroplasts in the spring and summer (Senser et al., 1975). For Italian arum (Arum italicum) fruits, greening proceeds after the fruits are formed. As the green color emerges, the amyloplasts are converted to chloroplasts with thylakoid membrane development and the plastoglobules increase in number and size (Bonora et al., 2000).

\section{From Chromoplasts}

Reversible changes from chromoplast to chloroplast are called regreening and can be found in citrus fruits (Mayfield and Huff, 1986), pumpkin (Devidé and Ljubešiæ, 1974), and 
TABLE 1 | Plastid transitions according to plant phenotypes in the view of greening status.

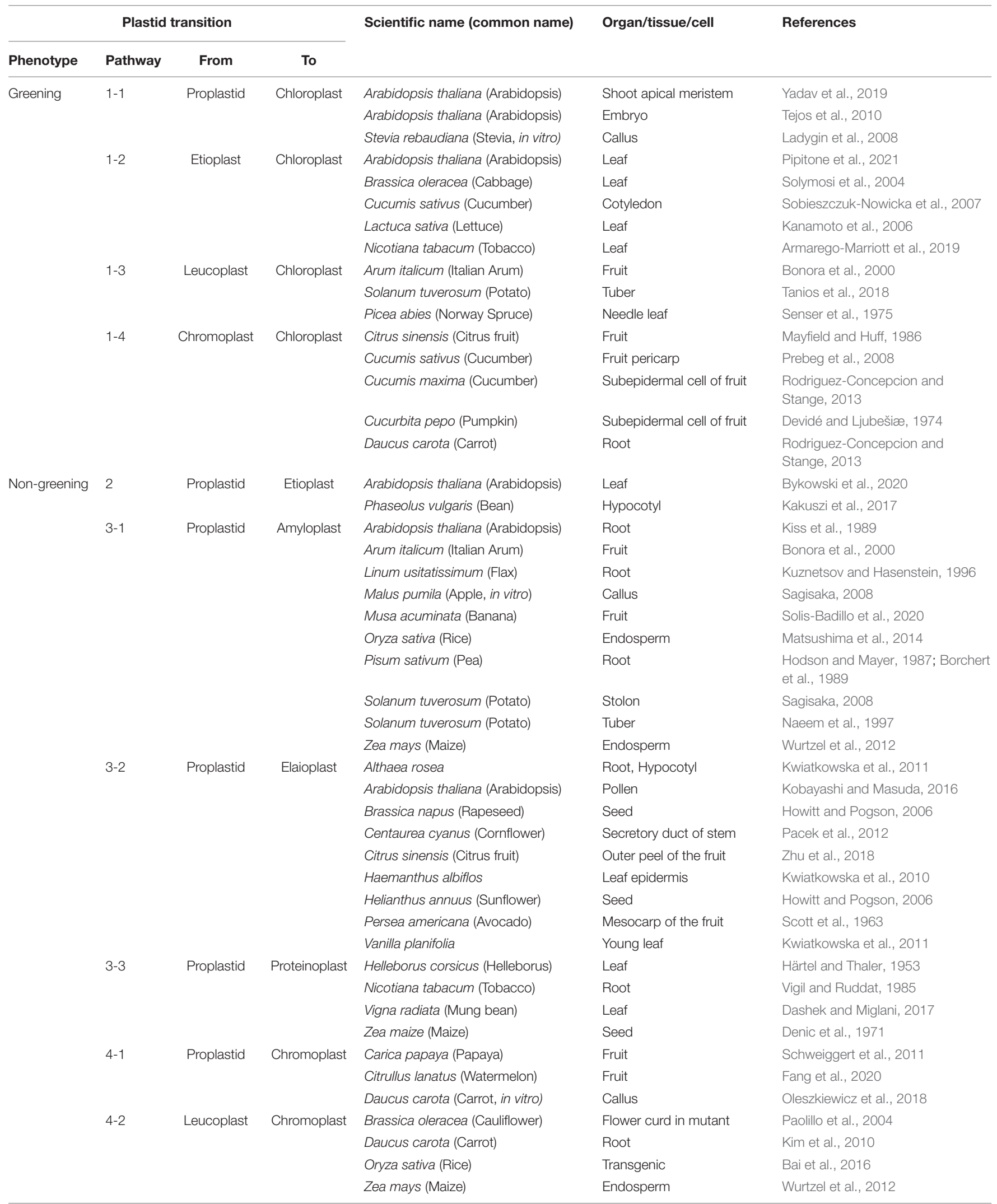


TABLE 1 | Continued

\begin{tabular}{|c|c|c|c|c|c|c|}
\hline \multicolumn{4}{|c|}{ Plastid transition } & \multirow[t]{2}{*}{ Scientific name (common name) } & \multirow[t]{2}{*}{ Organ/tissue/cell } & \multirow[t]{2}{*}{ References } \\
\hline Phenotype & Pathway & From & To & & & \\
\hline & $4-3$ & Chloroplast & Chromoplast & Arum italicum (Italian Arum) & Fruit & Bonora et al., 2000 \\
\hline & & & & Capsicum frutescens (Pepper) & Fruit & Jeong et al., 2020 \\
\hline & & & & Lilium longiflorum (Lily) & Flower & Juneau et al., 2002 \\
\hline & & & & Solanum lycopersicum (Tomato) & Fruit & Wang et al., 2020 \\
\hline \multirow[t]{3}{*}{ De-greening } & $5-1$ & Chloroplast & Leucoplast & Arabidopsis thaliana (Arabidopsis) & Flower petal & Pyke and Page, 1998 \\
\hline & $5-2$ & Chloroplast & Gerontoplast & Arabidopsis thaliana (Arabidopsis) & Leaf & Evans et al., 2010 \\
\hline & & & & Jatropha curcas (Jatropha) & Seed inner integument & Shah et al., 2016 \\
\hline
\end{tabular}

Pathway numbers correspond to those in the schematic diagram in Figure 1.

cucumber fruits (Prebeg et al., 2008; Rodriguez-Concepcion and Stange, 2013). Cucumber thylakoids are decomposed as the fruit matures, and then the thylakoid is reconstituted due to regreening. The plastids of mature fruit and the regreened chloroplasts show morphological similarities, which means re-differentiation of the plastids. Reconstitution of the thylakoids begins with membrane-bound bodies, and surface expansion and fragmentation occur. Afterward, tubules and double-membrane sheets are formed. The plastoglobuli remain in the plastid even during reconstruction. This transition implies that several types of membrane structures are associated with the plastid envelope during chloroplast re-differentiation (Prebeg et al., 2008). Light is regarded as a key factor that greatly influences regreening. As a result of irradiating the citrus fruit Valencia orange with a blue LED light, the tissue was gradually greened, and after 4 weeks, the chlorophyll content was approximately twice as high as that of the unirradiated tissue (Ma et al., 2020). In addition, the roots of the carrots were also completely altered by exposure to the light, and converted from $\beta$-carotene-rich chromoplasts to lutein-containing chloroplasts (Rodriguez-Concepcion and Stange, 2013).

\section{Development of Proplastids Into Etioplasts: Non-greening Phenotype}

When seeds are buried underground without light, but with sufficient environmental conditions for germination, the proplastids can develop into etioplasts while the plants etiolate. This transition is widely adopted by most plants and is an efficient strategy for seedlings in light-seeking circumstances. Until the photosynthetic tissues reach a light source, etioplasts develop with stacking prolamellar bodies and numerous small plastoglobuli (Rodríguez-Villalón et al., 2009). According to studies on Arabidopsis and soybeans, etioplast formation is influenced by etiolation time, and the efficient tubular-lamellar arrangement affects subsequent vegetative growth (Kakuszi et al., 2017; Bykowski et al., 2020). The key element to maintaining etioplasts is the completely dark environment. The loss of negative regulators of photomorphogenesis (DET1, COP1, and a combination of PIFs) inhibited etioplast differentiation in dark conditions, thereby suggesting that etioplasts develop in dark conditions via the negative regulation of photomorphogenesis (Wei et al., 1994; Sperling et al., 1998; Stephenson et al., 2009).

\section{Development of Proplastids Into Leucoplasts: Non-greening Phenotype To Amyloplasts}

The development of amyloplasts can be observed in most tissues with high-starch contents. Starch is often stored in the root tissues of plants, such as with Arabidopsis (Kiss et al., 1989), flax (Kuznetsov and Hasenstein, 1996), and pea (Hodson and Mayer, 1987; Borchert et al., 1989). Furthermore, the tubers and stolons of potatoes are representative organs that accumulate amyloplasts (Naeem et al., 1997; Sagisaka, 2008). In the case of fruits, starch mainly accumulates during the "maturation" period, such as with banana (Solis-Badillo et al., 2020) and Italian arum (Bonora et al., 2000). For apples, in vitro experiments showed that the formation of amyloplasts occurs in the callus and endosperm (Sagisaka, 2008). For rice and wheat, the accumulation of amyloplasts mainly found in the endosperm (Wurtzel et al., 2012). In amyloplasts, starch is produced in the matrix space (stroma) and forms starch grains, which exhibit different morphologies depending on the plant species and have been intensively studied in various staple crops. The diameter of starch grains in corn, rice and sorghum are about $10,10-20$, and $15-25 \mu \mathrm{m}$, respectively, while less than $10 \mu \mathrm{m}$ in barley and wheat (Matsushima et al., 2014; Matsushima and Hisano, 2019).

\section{To Elaioplasts}

The elaioplasts have been largely reported in flowers and they can be found in their ovaries, ovary epidermis, and innermost tapetum cell of the anther wall (Chen et al., 1988; Ciampolini et al., 1993; Kwiatkowska et al., 2010, 2011). Elaioplasts were also reported in secretory ducts of the stem and leaf epidermis from Centaurea cyanus and Haemanthus albiflos (Kwiatkowska et al., 2010; Pacek et al., 2012), young leaves of Vanilla planifolia, roots, hypocotyls of Althaea rosea (Kwiatkowska et al., 2011), seeds of canola and sunflower (Howitt and Pogson, 2006; Lersten et al., 2006), mesocarp of the fruit in avocados (Scott et al., 1963), and green pericarps of citrus fruits (Zhu et al., 2018). The formation of elaioplasts has been reported to occur by a diverse range of mechanisms that vary by species. Observations of elaioplast differentiation in the tapetal cells of Arabidopsis 
thaliana, showed that the transition from proplastid to elaioplast occurred at "stage 9" with spot like structures that shapes like plastoglobuli (Suzuki et al., 2013).

\section{To Proteinoplast}

Proteinoplasts have been studies in detail from the roots of tobacco (Vigil and Ruddat, 1985). They are mainly distributed in the vacuolate and root cap cells of the root and accumulate in the slender tubules of the plastids. As cells divide, protein accumulation occurs, tubules expand, and protein bodies of dense spheroidal structures appear. Proteinoplasts were also observed in the leaves and seeds of Helleborus corsicus and Zea maize, respectively (Härtel and Thaler, 1953; Denic et al., 1971). In addition, a proteinoplast with a granular matrix containing a large amount protein was reported in the leaves of mung bean (Dashek and Miglani, 2017).

\section{Development of Chloroplast Into Chromoplasts: Non-greening Phenotype From Proplastid}

The transition from proplastid to chromoplast is often found during fruit maturation. Representative examples of the transition from proplastid to chromoplast can be found in watermelon (Citrullus lanatus), papaya (Carica papaya), and carrot calluses. In papaya during early white maturation, undifferentiated proplastids and globular plastids were dominant, but intermediate plastids such as the chloroplasts and amyloplasts were not found until chromoplasts developed. They were thus thought to have differentiated from the proplastids (Schweiggert et al., 2011). In watermelon, similar chromoplast development with an analysis of the pattern of each color step has been reported. When looking at the plastid differentiation patterns of watermelon, the accumulation of carotenoids and chromoplasts appeared according to the maturity of the fruit. In addition, many plastoglobuli were accumulated in the chromoplasts of yellow and orange watermelons when compared to white watermelons. The red watermelon chromoplasts formed an elongated or irregular structure, and the number of plastoglobuli further increased (Fang et al., 2020). In the carrot callus system, proplastids could be converted into chromoplasts during callus differentiation. In the case of pale-yellow carrot calluses, the carotenoid content was low while most of the plastids were proplastids. Conversely, for dark-orange carrot calluses, there were a large amount of chromoplasts, with high carotenoid contents, while the number of proplastids was significantly reduced (Oleszkiewicz et al., 2018). Meanwhile, the Arabidopsis callus contains proplastids, but the induced or stable overexpression of a phytoene synthase gene (PSY) showed the increased carotenoid contents with the chromoplast development (Maass et al., 2009; Rodríguez-Villalón et al., 2009).

\section{From Leucoplasts}

This transition occurs during the maturation of fruits, flowers, and roots (Sun et al., 2018). Relatively well-studied cases for this transition are carrots (Daucus carota) and orange cauliflower mutants (Brassica oleracea L. var. botrytis). In the case of carrot roots, the types of plastids present differed markedly depending on the color. The root of orange carrots was rich in chromoplasts with crystal-shaped structure due to carotene, whereas white carrots had fewer chromoplasts and no crystal-shaped structure. Instead, the white carrot roots showed amyloplasts filled with starch grains, and the total number of the chromoplasts and amyloplasts did not show any significant differences (Kim et al., 2010). In the case of orange cauliflower, the plastid of white wild-type tissues was characterized by leucoplasts, where orange-colored mutants have chromoplasts with accumulated $\beta$-carotene (Paolillo et al., 2004). Chromoplast transitions could also be found in the endosperms of rice and corn, which are mostly formed by amyloplasts. Although wild-type rice endosperms do not produce carotenoids, a combination of multiple carotenogenic genes such as 1deoxy-D-xylulose 5-phosphate synthase (DXS), PSY, bacterial phytoene desaturase (CRTI), and ORANGE (OR) could result in chromoplast development (Ye et al., 2000; Wurtzel et al., 2012; Bai et al., 2016; You et al., 2020).

\section{From Chloroplasts}

Chromoplasts synthesize and store carotenoids and are mainly found in petals and fruits, which are organs related to reproduction, but they can also occur in the leaves and roots. The transition from chloroplast to chromoplast starts from the breakdown of thylakoids and chlorophyll. This is followed by the increases of plastoglobuli size and the biosynthesis and accumulation of the carotenoids (Wrischer and Devide, 2002). Representative cases showing the irreversible process from chloroplast to chromoplast were found in tomato (Solanum lycopersicum) (Egea et al., 2011; Barsan et al., 2012; D’Andrea et al., 2014), red pepper (Jeong et al., 2020), Italian arum (Bonora et al., 2000), and lily (Lilium longiflorum) (Juneau et al., 2002). Interestingly, with single gene overexpression, such as the AtPSY overexpression line in Arabidopsis and the Pantoea ananatis phytoene synthase ( $c r t B$ ) overexpression by viral vector in tobacco were able to develop the chromoplast from leaf tissues (Maass et al., 2009; Majer et al., 2017). According to a recent report about the modifications of membrane structure in tomato chloroplasts, it was observed that the inner envelope membrane and thylakoid membranes disappeared during the transition to chromoplasts, and new factors (plastoglobules and crystal remnants, etc.) were generated through membrane fusion and vesicles budding (Wang et al., 2020).

\section{Development of Chloroplasts: De-Greening Phenotype To Leucoplasts}

One of the well-known examples for de-greening to leucoplast is Arabidopsis flower development. Young petals that have just bloomed contain green chloroplasts throughout their structures, but as the petals expand and develop, they lose chlorophyll and these regenerate into white bodies. During this process, plastids break down chlorophyll, and carotenoids are not synthesized (Pyke and Page, 1998; Irish, 2008). 


\section{To Gerontoplasts}

Gerontoplasts are known to occur in both photosynthetic and non-photosynthetic organs as they appear with aging. In general, as chloroplasts age, although their outer shell remains intact, plastoglobuli are formed along with lipophilic substances, and extensive structural changes of the thylakoid membrane occur. In Arabidopsis, observations of gerontoplasts found that they had a degenerated outer shell and thylakoid membranes of chloroplast, enlarged plastoglobuli and grana, and these are gradually increased as they aged (Evans et al., 2010). Another study of the structural characteristics of gerontoplasts during Jatropha curcas seed development, found that the inner membrane system (thylakoid membrane and plastid outer envelope membrane) decomposed, and then there was gradual decomposition of the substrate and plastoglobuli (Shah et al., 2016).

\section{REGULATORS OF PLASTID TRANSITIONS}

Recently, research on the regulatory pathways for plastids has largely expanded with many astonishing findings. So, due to considering the diversity and complexity of the plastid, most of the reviews for plastid related signals focused on specific aspects, such as plastid differentiation (Liebers et al., 2017; Knudsen et al., 2018; Sadali et al., 2019), light signals (López-Juez, 2007; Larkin and Ruckle, 2008; Larkin, 2014), redox control (Toyoshima et al., 2005), regulation and retrograde signals (Rodermel, 2001; Nott et al., 2006; Pogson et al., 2008; Kleine et al., 2009; Chi et al., 2013; Singh et al., 2015; Sun et al., 2018; Sun and Li, 2020), evolution (Reyes-Prieto et al., 2007; Archibald, 2009; Wicke et al., 2011; Keeling, 2013), and hormonal regulation (Al-Babili and Bouwmeester, 2015; Liu et al., 2017). In this review, we focused on the post-transcriptional regulation and newly found regulators for plastid transitions (Figure 2).

\section{Chloroplast Development}

Light is the primary signal for chloroplast development. Different ranges in wavelength are perceived by different photoreceptors, for example, UV-B is identified by UV RESISTANCE LOCUS 8 (UVR8), UV-A and blue light are identified by cryptochromes (CRYs) and phototropins, red light and far-red light are identified by phytochrome-red (Pr) and phytochrome-far-red (Pfr), respectively, as the interconvertible form of phytochromes (Paik and Huq, 2019). To take advantage of rapid response, the plants use post-transcriptional regulation by transferring the signal to E3 ligase mediated protein degradation pathways. In CULLIN4 (CUL4) type E3 ligase complex, CUL4 and UV-DAMAGED DNA BINDING PROTEIN1 (DDB1) consist of fundamental structures while CONSTITUTIVE PHOTOMORPHOGENICs (COPs), SUPRESSOR OF phyAs (SPAs), and DE-ETIOLATED 1 (DET1) have target-specificity functions (Lau and Deng, 2012). The COP1-SPA1 complex is a core regulator for light perception by the UVR8, CRY1 receptors and phytochrome responses (Wang et al., 2001; Saijo et al., 2003; Huang et al., 2013; Martínez et al., 2018). When UVR8 and CRY1 are activated by light, they inactivate COP1 and exported COP1 protein to the cytosolic region from the nucleus and, consequently, block the ubiquitination of ELONGATED HYPOCOTYL 5 (HY5) protein (Lau and Deng, 2012). The COP10-DET1 complex was also reported to be involved in the ubiquitination of Long Hypocotyl in Far-Red 1 (HFR1) (Yang et al., 2005) and GOLDEN2-LIKE 1 (GLK1) (Tang et al., 2016). HY5, HYH, and HFR1 were reported as positive transcriptional regulators used to assemble light signals for hypocotyl elongation and early light responses. GLKs also binds to the $32-88$ aa region of DET1 and the protein stability of GLKs are increased by blocking ubiquitination mediated protein degradation (Tang et al., 2016). GLKs are core positive regulators for chloroplast development based on their mutant phenotypes, while the phenotype of $g l k 1 / g l k 2$ double KO still had chloroplasts which indicates the possibility of another regulator (Fitter et al., 2002; Wang et al., 2013). Two genes were reported for similar but minor phenotypes when compare to GLKs, called GATA, NITRATE-INDUCIBLE, CARBON-METABOLISM INVOLVED (GNC), and GNC-LIKE (GNL) (Richter et al., 2010). When the lights on, together with the release of the E3 ligase degradation pathway, there was transcriptional inhibition of $H Y 5, H Y H$, and HRF1 by PHYTOCHROME INTERACTING FACTORS (PIFs), and ethylene-insensitive 3 (EIN3) was released by the degradation of the PIFs and EIN3 (Zhong et al., 2009). This also triggered the transcriptional regulation of core positive regulators to give synergetic effects. Pseudo-Etiolation in Light/DEEP GREEN PANICLE1 (AtPEL1) was primarily reported in the Arabidopsis Full-length cDNA Over-eXpressing gene hunting system (FOX hunting system) for the chlorophyll repression gene (Ichikawa et al., 2006; Llorente et al., 2017) and, interestingly, with the same FOX hunting system, the ectopic overexpression of OsGLK1 convert proplastid into chloroplast in rice callus (Nakamura et al., 2009). The further analysis showed a binding affinity of OsPEL1 with OsGLK1 and OsGLK2 in rice. Although the regulatory model was not well-established and the function of PEL in rice was restricted to the panicle, AtPEL1 represses the activation activity of OsGLK1 (Zhang et al., 2020). With the assembly of positive regulators, the core enzymatic proteins for chloroplast biogenesis, the tetrapyrrole biosynthesis pathway, Photosynthesis Associated Nuclear Genes and PEP-associated proteins (PAPs), SIGMA factors (SIG), PRIN2 were elevated (Kindgren et al., 2012; Kobayashi and Masuda, 2016; Hernández-Verdeja et al., 2020).

\section{Chromoplast Development}

Several regulators play essential roles in chromoplast transition, but they are not as well-established as in chloroplasts. During fruit ripening in tomato (Solanum lycopersicum), the MADSbox transcription factor RIPENING INHIBITOR (RIN) has been reported as core positive regulator that activates rate-limiting enzymes in carotenoid pathways (Martel et al., 2011). TOMATO AGAMOUS LIKE1 (TAGL1) forms a complex with RIN and lycopene in tomato fruits was fortified by TAGL1 overexpression (Itkin et al., 2009; Lü et al., 2018). A non-functional mutant of the NAC transcription factor called NON-RIPENING (NOR) was reported for a similar phenotype of the rin mutant by retardation of the plastid transition (Giovannoni, 2004, 2007). 


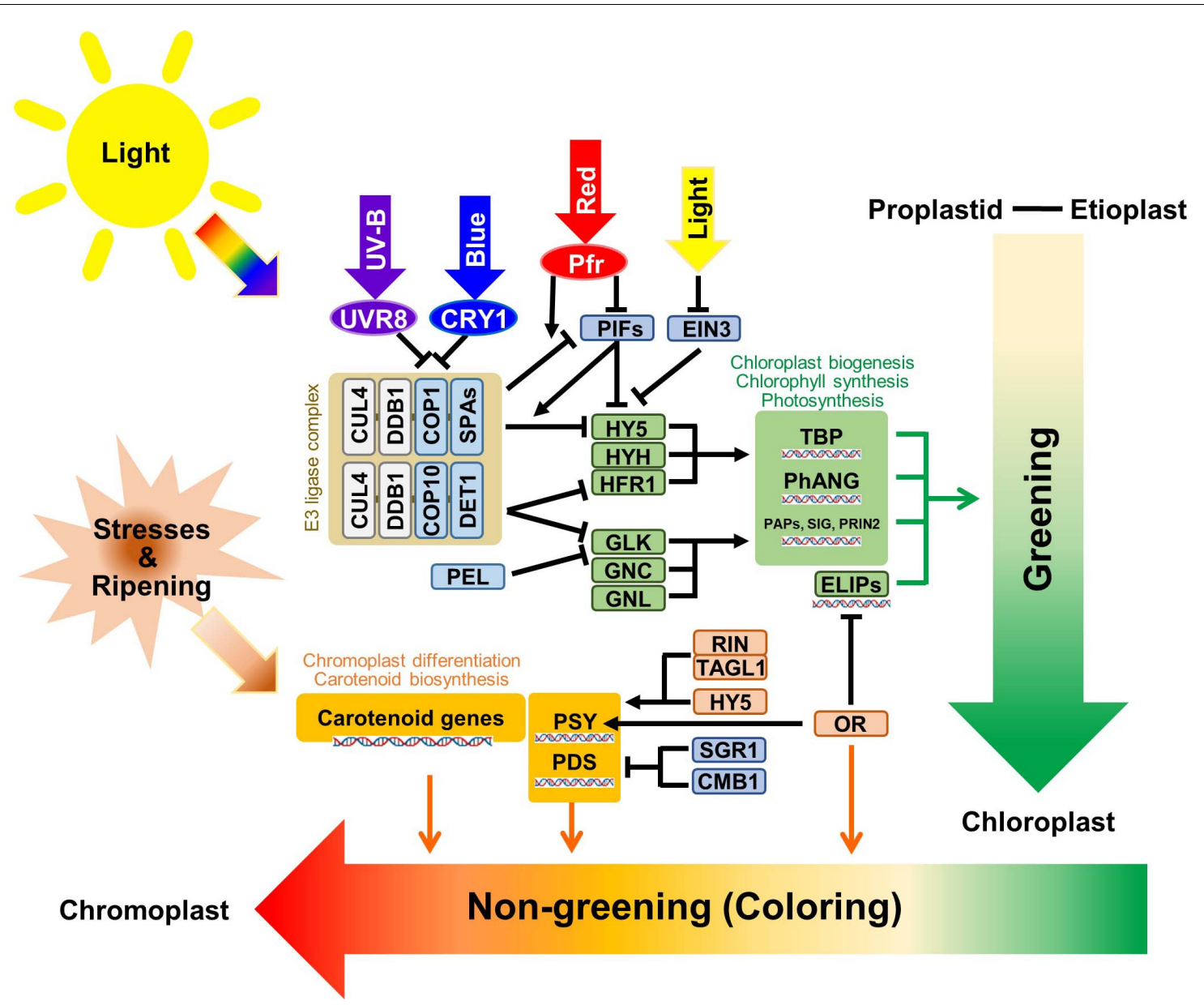

FIGURE 2 | Schematic diagram of the plastid transition regulations. The regulatory mechanisms of greening and non-greening plastid interconversions are briefly summarized with core transcriptional and post-translational regulators. The light signals from different wavelengths are indicated with thick arrows with representative colors. The photoreceptors are shown with circles, while regulatory genes are shown within rectangular boxes. E3 ligase complexes, chloroplast biogenesis related enzymes, and chromoplast biogenesis related enzymes were categorized with white brown, green, and orange-colored boxes, respectively. DNA helix symbols represent the transcriptional regulation of genes. Green lines indicate the direct effects of "Greening" while red lines indicate the direct effects of "Non-greening".

A light-induced bZIP transcription factor HY5 directly binds to a promoter for carotenoid biosynthesis rate-limiting enzymes, $P S Y$ and phytoene desaturase (PDS), and activates their transcription (Toledo-Ortiz et al., 2014). Another positive regulator, OR, was responsible for the generation of chromoplasts in floral organs of cauliflower (Brassica oleracea var. botrytis) (Li et al., 2003; Lu et al., 2006). OR was also reported to have holdase chaperone activity for PSY, as it enhanced the PSY protein stability and increased its enzymatic activity (Welsch et al., 2018). In Arabidopsis, further analysis found that the OR binds with a bHLH transcription factor TEOSINTE BRANCHED, CYCLOIDEA AND PCF (TCP14) to increase the stability and transcription level of EARLY LIGHT-INDUCIBLE PROTEINS (ELIP1 and ELIP2), which are chlorophyll binding proteins for chloroplast development (Sun et al., 2019). And diverse mutant analysis with different species indicates the essential roles of OR gene in chromoplast development (Kim et al., 2018; Welsch et al., 2020). Meanwhile, as repressive regulators,
STAY-GREEN 1 (SISGR1) in tomato directly interacted with SIPSY1 and could inhibit its protein levels. Furthermore, the repression of SlSGR1 in transgenic tomato fruits resulted in the elevation of SlPSY1 mRNA accumulations and the acceleration of chromoplast interconversion times (Luo et al., 2013). One of the MADS-box proteins called SlCMB1, which belongs to the same SEP sub-clade with RIN, was also reported to have an essential role in chromoplast development in tomato. The SlCMB1-RNAi fruits have decreased PSY1 and PDS expression, and decreased ethylene production and related signal pathway genes (Zhang et al., 2018). Furthermore, the exogenous induction of rate-limiting carotenoid biosynthesizing enzymes able to trigger the interconversion of plastids to chromoplasts (Ha et al., 2019; Llorente et al., 2020). Diverse environmental stresses and developmental signals including ripening could also trigger chromoplast development through the induction of carotenoid biosynthesis (Bouvier et al., 1998; Sadali et al., 2019). 


\section{CONCLUSION AND PERSPECTIVE}

From the overview of diverse representative, sophisticate adjustment of plastid interconversion revealed as essential element for multiple agronomic traits. Not only the photosynthesis related yield potential, many plant-derived biproducts including starch, lipid, protein and secondary metabolites have been determined by development and interconversion of plastid. Although, under the demands from the plants are continuously increased with limited environmental condition, this review suggest the study of plastid can be the breakthrough solution and supports the plastid research by representative scientific reports of plastid interconversion types and core regulators for molecular modification candidates. Finally, the candidates from the well summarized molecular pathway for plastid interconversion can be applied as target gene for

\section{REFERENCES}

Al-Babili, S., and Bouwmeester, H. J. (2015). Strigolactones, a novel carotenoidderived plant hormone. Annu. Rev. Plant Biol. 66, 161-186. doi: 10.1146/ annurev-arplant-043014-114759

Archibald, J. M. (2009). The puzzle of plastid evolution. Curr. Biol. 19, R81-R88. doi: 10.1016/j.cub.2008.11.067

Armarego-Marriott, T., Kowalewska, Ł, Burgos, A., Fischer, A., Thiele, W., Erban, A., et al. (2019). Highly resolved systems biology to dissect the etioplast-tochloroplast transition in tobacco leaves. Plant Physiol. 180, 654-681. doi: 10. 1104/pp.18.01432

Austin, J. R., Frost, E., Vidi, P. A., Kessler, F., and Staehelin, L. A. (2006). Plastoglobules are lipoprotein subcompartments of the chloroplast that are permanently coupled to thylakoid membranes and contain biosynthetic enzymes. Plant Cell 18, 1693-1703. doi: 10.1105/tpc.105.039859

Bai, C., Capell, T., Berman, J., Medina, V., Sandmann, G., Christou, P., et al. (2016). Bottlenecks in carotenoid biosynthesis and accumulation in rice endosperm are influenced by the precursor-product balance. Plant Biotechnol. J. 14, 195-205. doi: $10.1111 /$ pbi.12373

Barsan, C., Zouine, M., Maza, E., Bian, W., Egea, I., Rossignol, M., et al. (2012). Proteomic analysis of chloroplast-to-chromoplast transition in tomato reveals metabolic shifts coupled with disrupted thylakoid biogenesis machinery and elevated energy-production components. Plant Physiol. 160, 708-725. doi: 10. 1104/pp.112.203679

Biswal, B., Mohapatra, P. K., Biswal, U. C., and Raval, M. K. (2012). "Leaf senescence and transformation of chloroplasts to gerontoplasts," in Photosynthesis Advances in Photosynthesis and Respiration, Vol. 34, eds J. EatonRye, B. Tripathy, and T. Sharkey (Dordrecht: Springer), 217-230. doi: 10.1007/ 978-94-007-1579-0_10

Boland, M. J., and Schubert, K. R. (1983). Biosynthesis of purines by a proplastid fraction from soybean nodules Glycine max. Arch. Biochem. Biophys. 220, 179-187. doi: 10.1016/0003-9861(83)90398-3

Bonora, A., Pancaldi, S., Gualandri, R., and Fasulo, M. P. (2000). Carotenoid and ultrastructure variations in plastids of Arum italicum Miller fruit during maturation and ripening. J. Exp. Bot. 51, 873-884. doi: 10.1093/jexbot/51.346. 873

Borchert, S., Grosse, H., and Heldt, H. W. (1989). Specific transport of inorganic phosphate, glucose 6-phosphate, dihydroxyacetone phosphate and 3-phosphoglycerate into amyloplasts from pea roots. FEBS Lett. 253, 183-186. doi: 10.1016/0014-5793(89)80955-X

Bouvier, F., Backhaus, R. A., and Camara, B. (1998). Induction and control of chromoplast-specific carotenoid genes by oxidative stress. J. Biol. Chem. 273, 30651-30659. doi: 10.1074/jbc.273.46.30651

Brillouet, J. M., Verdeil, J. L., Odoux, E., Lartaud, M., Grisoni, M., and Conéjéro, G. (2014). Phenol homeostasis is ensured in vanilla fruit by storage under solid improving multiple agronomic traits which are related to plastid interconversion.

\section{AUTHOR CONTRIBUTIONS}

S-HH designed the concept and the organization of the manuscript. HC and TY wrote and edited the manuscript. All authors have read and approved the final manuscript.

\section{FUNDING}

This work was supported by the National Research Foundation of Korea (NRF) grant funded by the Ministry of Science and ICT (No. 2021R1A2C2012227 to S-HH and No. 2020R1I1A1A01073720 to HC).

form in a new chloroplast-derived organelle, the phenyloplast. J. Exp. Bot. 65, 2427-2435. doi: 10.1093/jxb/eru126

Bykowski, M., Mazur, R., Buszewicz, D., Szach, J., Mostowska, A., and Kowalewska, ŁJ. (2020). Spatial nano-morphology of the prolamellar body in etiolated Arabidopsis thaliana plants with disturbed pigment and polyprenol composition. Front. Cell Dev. Biol. 8:586628. doi: 10.3389/fcell.2020.58 6628

Carde, J. (1984). Leucoplasts: a distinct kind of organelles lacking typical 70S ribosomes and free thylakoids. Eur. J. Cell Biol. 34, 18-26.

Chen, R., Rosen, E., and Masson, P. H. (1999). Gravitropism in higher plants. Plant Physiol. 120, 343-350. doi: 10.1104/pp.120.2.343

Chen, Z. K., Wang, F. H., and Zhou, F. (1988). On the origin, development and ultrastructure of the orbicuies and pollenkitt in the tapetum of Anemarrhena asphodeloides (Liliaceae). Grana 27, 273-282. doi: 10.1080/00173138809429949

Chi, W., Sun, X., and Zhang, L. (2013). Intracellular signaling from plastid to nucleus. Annu. Rev. Plant Biol 64, 559-582. doi: 10.1146/annurev-arplant050312-120147

Ciampolini, F., Nepi, M., and Pacini, E. (1993). "Tapetum development in Cucurbita pepo (Cucurbitaceae)," in The Tapetum Plant Systematics and Evolution (Supplementum 7), Vol. 7, eds M. Hesse, E. Pacini, and M. Willemse (Vienna: Springer), 13-22. doi: 10.1007/978-3-7091-6661-1_2

Cruz, A. B., Bianchetti, R. E., Alves, F. R. R., Purgatto, E., Peres, L. E. P., Rossi, M., et al. (2018). Light, ethylene and auxin signaling interaction regulates carotenoid biosynthesis during tomato fruit ripening. Front. Plant Sci. 9:1370. doi: 10.3389/fpls.2018.01370

Dall'Osto, L., Bassi, R., and Ruban, A. (2014). "Photoprotective mechanisms: carotenoids," in Plastid Biology Advances in Plant Biology, Vol. 5, eds S. Theg and F. A. Wollman (New York, NY: Springer), 393-435. doi: 10.1007/978-14939-1136-3_15

Dall'Osto, L., Caffarri, S., and Bassi, R. (2005). A mechanism of nonphotochemical energy dissipation, independent from PsbS, revealed by a conformational change in the antenna protein CP26. Plant Cell 17, 1217-1232. doi: 10.1105/ tpc.104.030601

Dall'Osto, L., Cazzaniga, S., North, H., Marion-Poll, A., and Bassi, R. (2007). The Arabidopsis aba4-1 mutant reveals a specific function for neoxanthin in protection against photooxidative stress. Plant Cell 19, 1048-1064. doi: 10.1105/ tpc.106.049114

D’Andrea, L., Amenós, M., and Rodríguez-Concepción, M. (2014). “Confocal laser scanning microscopy detection of chlorophylls and carotenoids in chloroplasts and chromoplasts of tomato fruit," in Plant Isoprenoids, Vol. 1153, ed. M. Rodríguez-Concepción (Dordrecht: Springer), 227-232. doi: 10.1007/9781-4939-0606-2_16

Dashek, W. V., and Miglani, G. S. (2017). Plant Cells and Their Organelles. In Vacuoles and Protein Bodies, Vol. 2. Chichester: Wiley Online Library, 351-370. doi: 10.1002/9781118924846 
Denic, M., Dzamic, M., and Dumanovic, J. (1971). On the role of proteinoplasts in genetic regulation of amino acid composition of maize endosperm proteins. Agrochimica 15, 564-568. doi: 10.1007/978-94-009-6801-1_8

Devidé, Z., and Ljubešić, N. (1974). The reversion of chromoplasts to chloroplasts in pumpkin fruits. Z. Pflanzenphysiol. 73, 296-306. doi: 10.1016/s0044-328x(74) 80130-3

Egea, I., Bian, W., Barsan, C., Jauneau, A., Pech, J. C., Latché, A., et al. (2011). Chloroplast to chromoplast transition in tomato fruit: spectral confocal microscopy analyses of carotenoids and chlorophylls in isolated plastids and time-lapse recording on intact live tissue. Ann. Bot. 108, 291-297. doi: 10.1093/ aob/mcr 140

Evans, I., Rus, A., Belanger, E., Kimoto, M., and Brusslan, J. A. (2010). Dismantling of Arabidopsis thaliana mesophyll cell chloroplasts during natural leaf senescence. Plant Biol. 12, 1-12. doi: 10.1111/j.1438-8677.2009.00206.x

Fang, X., Liu, S., Gao, P., Liu, H., Wang, X., Luan, F., et al. (2020). Expression of CIPAP and ClPSY1 in watermelon correlates with chromoplast differentiation, carotenoid accumulation, and flesh color formation. Sci. Hortic. 270, 109437. doi: $10.1016 /$ j.scienta.2020.109437

Ferguson, S. J. (1998). Nitrogen cycle enzymology. Curr. Opin. Chem. Biol. 2, 182-193. doi: 10.1016/s1367-5931(98)80059-8

Fernandez, O., Ishihara, H., George, G. M., Mengin, V., Flis, A., Sumner, D., et al. (2017). Leaf starch turnover occurs in long days and in falling light at the end of the day. Plant Physiol. 174, 2199-2212. doi: 10.1104/pp.17.00601

Fitter, D. W., Martin, D. J., Copley, M. J., Scotland, R. W., and Langdale, J. A. (2002). GLK gene pairs regulate chloroplast development in diverse plant species. Plant J. 31, 713-727. doi: 10.1046/j.1365-313X.2002.01390.x

Fujii, S., Nagata, N., Masuda, T., Wada, H., and Kobayashi, K. (2019). Galactolipids are essential for internal membrane transformation during etioplast-tochloroplast differentiation. Plant Cell Physiol. 60, 1224-1238. doi: 10.1093/pcp/ pcz041

Gajecka, M., Marzec, M., Chmielewska, B., Jelonek, J., Zbieszczyk, J., and Szarejko, I. (2020). Plastid differentiation during microgametogenesis determines green plant regeneration in barley microspore culture. Plant Sci. 291, 110321. doi: 10.1016/j.plantsci.2019.110321

Gayral, M., Fanuel, M., Rogniaux, H., Dalgalarrondo, M., Elmorjani, K., Bakan, B., et al. (2019). The spatiotemporal deposition of lysophosphatidylcholine within starch granules of maize endosperm and its relationships to the expression of genes involved in endoplasmic reticulum-amyloplast lipid trafficking and galactolipid synthesis. Plant Cell Physiol. 60, 139-151. doi: 10.1093/pcp/pcy198

Giovannoni, J. J. (2004). Genetic regulation of fruit development and ripening. Plant Cell 16, S170-S180. doi: 10.1105/tpc.019158

Giovannoni, J. J. (2007). Fruit ripening mutants yield insights into ripening control. Curr. Opin. Plant Biol. 10, 283-289. doi: 10.1016/j.pbi.2007.04.008

Greco, M., Chiappetta, A., Bruno, L., and Bitonti, M. B. (2012). In Posidonia oceanica cadmium induces changes in DNA methylation and chromatin patterning. J. Exp. Bot. 63, 695-709. doi: 10.1093/jxb/err313

Ha, S. H., Kim, J. K., Jeong, Y. S., You, M. K., Lim, S. H., and Kim, J. K. (2019). Stepwise pathway engineering to the biosynthesis of zeaxanthin, astaxanthin and capsanthin in rice endosperm. Metab. Eng. 52, 178-189. doi: 10.1016/j. ymben.2018.11.012

Hagemann, R. (2004). “The sexual inheritance of plant organelles," in Molecular Biology and Biotechnology of Plant Organelles, Vol. 1, eds H. Daniell and C. Chase (Dordrecht: Springer), 93-113. doi: 10.1007/978-1-4020-3166-3_4

Härtel, O., and Thaler, I. (1953). Die Proteinoplasten von Helleborus corsicus Willd. Protoplasma 42, 417-426. doi: 10.1007/BF01247925

Havaux, M., and Niyogi, K. K. (1999). The violaxanthin cycle protects plants from photooxidative damage by more than one mechanism. Proc. Natl. Acad. Sci. U.S.A. 96, 8762-8767. doi: 10.1073/pnas.96.15.8762

Hempel, J., Amrehn, E., Quesada, S., Esquivel, P., Jiménez, V. M., Heller, A., et al. (2014). Lipid-dissolved $\gamma$-carotene, $\beta$-carotene, and lycopene in globular chromoplasts of peach palm (Bactris gasipaes Kunth) fruits. Planta 240, 10371050. doi: 10.1007/s00425-014-2121-3

Hernández-Verdeja, T., Vuorijoki, L., and Strand, Å (2020). Emerging from the darkness: interplay between light and plastid signaling during chloroplast biogenesis. Physiol. Plant 169, 397-406. doi: 10.1111/ppl.13100

Hodson, M., and Mayer, A. M. (1987). Salt-induced changes in the distribution of amyloplasts in the root cap of excised pea roots in culture. Ann. Bot. 59, 499-503. doi: 10.1093/oxfordjournals.aob.a087343
Howitt, C. A., and Pogson, B. J. (2006). Carotenoid accumulation and function in seeds and non-green tissues. Plant Cell Environ. 29, 435-445. doi: 10.1111/j. 1365-3040.2005.01492.x

Huang, X., Ouyang, X., Yang, P., Lau, O. S., Chen, L., Wei, N., et al. (2013). Conversion from CUL4-based COP1-SPA E3 apparatus to UVR8-COP1-SPA complexes underlies a distinct biochemical function of COP1 under UVB. Proc. Natl. Acad. Sci. U.S.A. 110, 16669-16674. doi: 10.1073/pnas.13166 22110

Ichikawa, T., Nakazawa, M., Kawashima, M., Iizumi, H., Kuroda, H., Kondou, Y., et al. (2006). The FOX hunting system: an alternative gain-of-function gene hunting technique. Plant J. 48, 974-985. doi: 10.1111/j.1365-313X.2006.02 924.x

Irish, V. F. (2008). The Arabidopsis petal: a model for plant organogenesis. Trends Plant Sci. 13, 430-436. doi: 10.1016/j.tplants.2008.05.006

Ishida, H., Yoshimoto, K., Izumi, M., Reisen, D., Yano, Y., Makino, A., et al. (2008). Mobilization of rubisco and stroma-localized fluorescent proteins of chloroplasts to the vacuole by an ATG gene-dependent autophagic process. Plant physiol. 148, 142-155. doi: 10.1104/pp.108.122770

Itkin, M., Seybold, H., Breitel, D., Rogachev, I., Meir, S., and Aharoni, A. (2009). TOMATO AGAMOUS-LIKE 1 is a component of the fruit ripening regulatory network. Plant J. 60, 1081-1095. doi: 10.1111/j.1365-313X.2009.04064.x

Jarvis, P., and López-Juez, E. (2013). Biogenesis and homeostasis of chloroplasts and other plastids. Nat. Rev. Mol. Cell Biol. 14, 787-802. doi: 10.1038/nrm3702

Jeffery, J., Holzenburg, A., and King, S. (2012). Physical barriers to carotenoid bioaccessibility. Ultrastructure survey of chromoplast and cell wall morphology in nine carotenoid-containing fruits and vegetables. J. Sci. Food Agric. 92, 2594-2602. doi: 10.1002/jsfa.5767

Jeong, H. B., Jang, S. J., Kang, M. Y., Kim, S., Kwon, J. K., and Kang, B. C. (2020). Candidate Gene Analysis Reveals That the Fruit Color Locus C1 Corresponds to PRR2 in Pepper (Capsicum frutescens). Front. Plant Sci. 11:399. doi: 10.3389/ fpls.2020.00399

Juneau, P., Le Lay, P., Böddi, B., Samson, G., and Popovic, R. (2002). Relationship Between the Structural and Functional Changes of the Photosynthetic Apparatus During Chloroplast-Chromoplast Transition in Flower Bud of Lilium longiflorum. Photochem. Photobiol. 75, 377-381. doi: 10.1562/0031865520020750377RBTSAF2.0.CO2

Kakuszi, A., Solymosi, K., and Böddi, B. (2017). Transformation of plastids in soil-shaded lowermost hypocotyl segments of bean (Phaseolus vulgaris) during a 60-day cultivation period. Physiol. Plant. 159, 483-491. doi: 10.1111/ppl. 12519

Kanamoto, H., Yamashita, A., Asao, H., Okumura, S., Takase, H., Hattori, M., et al. (2006). Efficient and stable transformation of Lactuca sativa L. cv. Cisco (lettuce) plastids. Transgenic Res. 15, 205-217. doi: 10.1007/s11248-0053997-2

Keeling, P. J. (2013). The number, speed, and impact of plastid endosymbioses in eukaryotic evolution. Annu. Rev. Plant Biol. 64, 583-607. doi: 10.1146/annurevarplant-050312-120144

Kim, H. S., Ji, C. Y., Lee, C. J., Kim, S. E., Park, S. C., and Kwak, S. S. (2018). Orange: a target gene for regulating carotenoid homeostasis and increasing plant tolerance to environmental stress in marginal lands. J. Exp. Bot. 69, 3393-3400. doi: 10.1093/jxb/ery023

Kim, J. E., Rensing, K. H., Douglas, C. J., and Cheng, K. M. (2010). Chromoplasts ultrastructure and estimated carotene content in root secondary phloem of different carrot varieties. Planta 231, 549-558. doi: 10.1007/s00425-0091071-7

Kindgren, P., Norén, L., Lopez, JdDB, Shaikhali, J., and Strand, Å (2012). Interplay between Heat Shock Protein 90 and HY5 controls PhANG expression in response to the GUN5 plastid signal. Mol. Plant 5, 901-913. doi: 10.1093/mp/ ssr 112

Kiss, J. Z., Hertel, R., and Sack, F. D. (1989). Amyloplasts are necessary for full gravitropic sensitivity in roots of Arabidopsis thaliana. Planta 177, 198-206. doi: $10.1007 / \mathrm{BF} 00392808$

Kleine, T., Voigt, C., and Leister, D. (2009). Plastid signalling to the nucleus: messengers still lost in the mists? Trends Genet. 25, 185-192. doi: 10.1016/j.tig. 2009.02.004

Knudsen, C., Gallage, N. J., Hansen, C. C., Møller, B. L., and Laursen, T. (2018). Dynamic metabolic solutions to the sessile life style of plants. Nat. Prod. Rep. 35, 1140-1155. doi: 10.1039/c8np00037a 
Kobayashi, K., and Masuda, T. (2016). Transcriptional regulation of tetrapyrrole biosynthesis in Arabidopsis thaliana. Front. Plant Sci. 7:1811. doi: 10.3389/fpls. 2016.01811

Kuznetsov, O. A., and Hasenstein, K. H. (1996). Intracellular magnetophoresis of amyloplasts and induction of root curvature. Planta 198, 87-94. doi: 10.1007/ BF00197590

Kwiatkowska, M., Stępiński, D., Popłońska, K., Wojtczak, A., and Polit, J. (2010). "Elaioplasts" of Haemanthus albiflos are true lipotubuloids: cytoplasmic domains rich in lipid bodies entwined by microtubules. Acta Physiol. Plant. 32, 1189-1196. doi: 10.1007/s11738-010-0514-x

Kwiatkowska, M., Stepinski, D., Poplonska, K., Wojtczak, A., and Polit, J. (2011). 'Elaioplasts' identified as lipotubuloids in Althaea rosea, Funkia sieboldiana and Vanilla planifolia contain lipid bodies connected with microtubules. Acta Soc. Bot. Pol. 80, 211-219. doi: 10.5586/asbp.2011.036

Ladygin, V., Bondarev, N., Semenova, G., Smolov, A., Reshetnyak, O., and Nosov, A. M. (2008). Chloroplast ultrastructure, photosynthetic apparatus activities and production of steviol glycosides in Stevia rebaudiana in vivo and in vitro. Biol. Plant 52, 9-16. doi: 10.1007/s10535-008-0002-y

Larkin, R. M. (2014). Influence of plastids on light signalling and development. Philos. Trans. R. Soc. Lond. B Biol. Sci. 369, 20130232.

Larkin, R. M., and Ruckle, M. E. (2008). Integration of light and plastid signals. Curr. Opin. Plant Biol. 11, 593-599. doi: 10.1016/j.pbi.2008.10.004

Lau, O. S., and Deng, X. W. (2012). The photomorphogenic repressors COP1 and DET1: 20 years later. Trends Plant Sci. 17, 584-593. doi: 10.1016/j.tplants.2012. 05.004

Lersten, N. R., Czlapinski, A. R., Curtis, J. D., Freckmann, R., and Horner, H. T. (2006). Oil bodies in leaf mesophyll cells of angiosperms: overview and a selected survey. Am. J. Bot. 93, 1731-1739. doi: 10.3732/ajb.93.12.1731

Li, L., Lu, S., O’halloran, D. M., Garvin, D. F., and Vrebalov, J. (2003). Highresolution genetic and physical mapping of the cauliflower high- $\beta$-carotene gene Or (Orange). Mol. Genet. Genom. 270, 132-138. doi: 10.1007/s00438-0030904-5

Liebers, M., Grübler, B., Chevalier, F., Lerbs-Mache, S., Merendino, L., Blanvillain, R., et al. (2017). Regulatory shifts in plastid transcription play a key role in morphological conversions of plastids during plant development. Front. Plant Sci. 8:23. doi: 10.3389/fpls.2017.00023

Liu, X., Li, Y., and Zhong, S. (2017). Interplay between light and plant hormones in the control of Arabidopsis seedling chlorophyll biosynthesis. Front. Plant Sci. 8:1433. doi: 10.3389/fpls.2017.01433

Llorente, B., Martinez-Garcia, J. F., Stange, C., and Rodriguez-Concepcion, M. (2017). Illuminating colors: regulation of carotenoid biosynthesis and accumulation by light. Curr. Opin. Plant Biol. 37, 49-55. doi: 10.1016/j.pbi.2017. 03.011

Llorente, B., Torres-Montilla, S., Morelli, L., Florez-Sarasa, I., Matus, J. T., Ezquerro, M., et al. (2020). Synthetic conversion of leaf chloroplasts into carotenoid-rich plastids reveals mechanistic basis of natural chromoplast development. Proc. Natl. Acad. Sci. U.S.A. 117, 21796-21803. doi: 10.1073/pnas. 2004405117

López-Juez, E. (2007). Plastid biogenesis, between light and shadows. J. Exp. Bot. 58, 11-26. doi: 10.1093/jxb/erl196

Lopez-Juez, E., and Pyke, K. A. (2004). Plastids unleashed: their development and their integration in plant development. Int. J. Dev. Biol. 49, 557-577. doi: 10.1387/ijdb.051997el

Lü, P., Yu, S., Zhu, N., Chen, Y. R., Zhou, B., Pan, Y., et al. (2018). Genome encode analyses reveal the basis of convergent evolution of fleshy fruit ripening. Nat. Plants 4, 784-791. doi: 10.1038/s41477-018-0249-z

Lu, S., Van Eck, J., Zhou, X., Lopez, A. B., O’Halloran, D. M., Cosman, K. M., et al. (2006). The cauliflower Or gene encodes a DnaJ cysteine-rich domaincontaining protein that mediates high levels of $\beta$-carotene accumulation. Plant Cell 18, 3594-3605. doi: 10.1105/tpc.106.046417

Luo, Z., Zhang, J., Li, J., Yang, C., Wang, T., Ouyang, B., et al. (2013). A STAY-GREEN protein S 1 SGR 1 regulates lycopene and $\beta$-carotene accumulation by interacting directly with S 1 PSY 1 during ripening processes in tomato. New Phytol. 198, 442-452. doi: 10.1111/nph.12175

Ma, G., Zhang, L., Kitaya, Y., Seoka, M., Kudaka, R., Yahata, M., et al. (2020). Blue LED light induces regreening in the flavedo of Valencia orange in vitro. Food Chem. 335, 127621. doi: 10.1016/j.foodchem.2020.127621
Maass, D., Arango, J., Wüst, F., Beyer, P., and Welsch, R. (2009). Carotenoid crystal formation in Arabidopsis and carrot roots caused by increased phytoene synthase protein levels. PloS one 4:e6373. doi: 10.1371/journal.pone.0006373

Majer, E., Llorente, B., Rodríguez-Concepción, M., and Daròs, J. A. (2017). Rewiring carotenoid biosynthesis in plants using a viral vector. Sci. Rep. 7, 1-10. doi: $10.1038 /$ srep41645

Makino, A., and Osmond, B. (1991). Effects of nitrogen nutrition on nitrogen partitioning between chloroplasts and mitochondria in pea and wheat. Plant Physiol. 96, 355-362. doi: 10.1104/pp.96.2.355

Martel, C., Vrebalov, J., Tafelmeyer, P., and Giovannoni, J. J. (2011). The tomato MADS-box transcription factor RIPENING INHIBITOR interacts with promoters involved in numerous ripening processes in a COLORLESS NONRIPENING-dependent manner. Plant Physiol. 157, 1568-1579. doi: 10. 1104/pp.111.181107

Martínez, C., Nieto, C., and Prat, S. (2018). Convergent regulation of PIFs and the E3 ligase COP1/SPA1 mediates thermosensory hypocotyl elongation by plant phytochromes. Curr. Opin. Plant Biol. 45, 188-203. doi: 10.1016/j.pbi.2018.09. 006

Matsushima, R., and Hisano, H. (2019). Imaging amyloplasts in the developing endosperm of barley and rice. Sci. Rep. 9, 1-10. doi: 10.1038/s41598-019-40 424-w

Matsushima, R., Maekawa, M., Kusano, M., Kondo, H., Fujita, N., Kawagoe, Y., et al. (2014). Amyloplast-localized SUBSTANDARD STARCH GRAIN4 protein influences the size of starch grains in rice endosperm. Plant Physiol. 164, 623-636. doi: 10.1104/pp.113.229591

Mayfield, S. P., and Huff, A. (1986). Accumulation of chlorophyll, chloroplastic proteins, and thylakoid membranes during reversion of chromoplasts to chloroplasts in Citrus sinensis epicarp. Plant Physiol. 81, 30-35. doi: 10.1104/ pp.81.1.30

Møller, S. G. (2006). Plastids. Annual plant review. Vol 13. Ann. Bot. 97, 676-677. doi: $10.1093 / \mathrm{aob} / \mathrm{mcl} 018$

Mortimer, C. L., Misawa, N., Perez-Fons, L., Robertson, F. P., Harada, H., Bramley, P. M., et al. (2017). The formation and sequestration of nonendogenous ketocarotenoids in transgenic Nicotiana glauca. Plant Physiol. 173, 1617-1635. doi: $10.1104 /$ pp.16.01297

Naeem, M., Tetlow, I., and Emes, M. J. (1997). Starch synthesis in amyloplasts purified from developing potato tubers. Plant J. 11, 1095-1103. doi: 10.1046/ j.1365-313X.1997.11051095.x

Nakamura, H., Muramatsu, M., Hakata, M., Ueno, O., Nagamura, Y., Hirochika, H., et al. (2009). Ectopic overexpression of the transcription factor OsGLK1 induces chloroplast development in non-green rice cells. Plant cell physiol. 50, 1933-1949. doi: 10.1093/pcp/pcp138

Nakamura, M., Nishimura, T., and Morita, M. T. (2019). Gravity sensing and signal conversion in plant gravitropism. J. Exp. Bot. 70, 3495-3506. doi: 10.1093/jxb/ erz158

Niyogi, K. K. (2000). Safety valves for photosynthesis. Curr. Opin. Plant Biol. 3, 455-460. doi: 10.1016/S1369-5266(00)00113-8

Niyogi, K. K., Björkman, O., and Grossman, A. R. (1997). The roles of specific xanthophylls in photoprotection. Proc. Natl. Acad. Sci. U.S.A. 94, 14162-14167. doi: 10.1073/pnas.94.25.14162

Nott, A., Jung, H.-S., Koussevitzky, S., and Chory, J. (2006). Plastid-to-nucleus retrograde signaling. Annu Rev. Plant Biol. 57, 739-759. doi: 10.1146/annurev. arplant.57.032905.105310

Oleszkiewicz, T., Klimek-Chodacka, M., Milewska-Hendel, A., Zubko, M., Stróż, D., Kurczyńska, E., et al. (2018). Unique chromoplast organisation and carotenoid gene expression in carotenoid-rich carrot callus. Planta 248, 1455 1471. doi: 10.1007/s00425-018-2988-5

Pacek, A., Stpiczyńska, M., Davies, K. L., and Szymczak, G. (2012). Floral elaiophore structure in four representatives of the Ornithocephalus clade (Orchidaceae: Oncidiinae). Ann. Bot. 110, 809-820. doi: 10.1093/aob/mcs 158

Paik, I., and Huq, E. (2019). Plant photoreceptors: Multi-functional sensory proteins and their signaling networks. Semin. Cell Dev. Biol. 92, 114-121. doi: 10.1016/j.semcdb.2019.03.007

Paolillo, D., Garvin, D., and Parthasarathy, M. V. (2004). The chromoplasts of Or mutants of cauliflower (Brassica oleracea L. var. botrytis). Protoplasma 224, 245-253. doi: 10.1007/s00709-004-0059-1 
Park, H., Kreunen, S. S., Cuttriss, A. J., DellaPenna, D., and Pogson, B. J. (2002). Identification of the carotenoid isomerase provides insight into carotenoid biosynthesis, prolamellar body formation, and photomorphogenesis. Plant Cell 14, 321-332. doi: 10.1105/tpc.010302

Pinard, D., and Mizrachi, E. (2018). Unsung and understudied: plastids involved in secondary growth. Curr. Opin. Plant Biol. 42, 30-36. doi: 10.1016/j.pbi.2018.01. 011

Pipitone, R., Eicke, S., Pfister, B., Glauser, G., Falconet, D., Uwizeye, C., et al. (2021). A multifaceted analysis reveals two distinct phases of chloroplast biogenesis during de-etiolation in Arabidopsis. eLife 10:e62709. doi: 10.7554/eLife.62709

Pogson, B. J., Woo, N. S., Förster, B., and Small, I. D. (2008). Plastid signalling to the nucleus and beyond. Trends Plant Sci. 13, 602-609. doi: 10.1016/j.tplants. 2008.08.008

Prebeg, T., Wrischer, M., Fulgosi, H., and Ljubešiæ, N. (2008). Ultrastructural characterization of the reversible differentiation of chloroplasts in cucumber fruit. J. Plant Biol. 51, 122-131. doi: 10.1007/BF03030721

Pyke, K. A., and Page, A. M. (1998). Plastid ontogeny during petal development in Arabidopsis. Plant Physiol. 116, 797-803. doi: 10.1104/pp.116.2.797

Quilichini, T. D., Douglas, C. J., and Samuels, A. L. (2014). New views of tapetum ultrastructure and pollen exine development in Arabidopsis thaliana. Ann. Bot. 114, 1189-1201. doi: 10.1093/aob/mcu042

Reyes-Prieto, A., Weber, A. P., and Bhattacharya, D. (2007). The origin and establishment of the plastid in algae and plants. Annu. Rev. Genet. 41, 147-168. doi: 10.1146/annurev.genet.41.110306.130134

Richter, R., Behringer, C., Müller, I. K., and Schwechheimer, C. (2010). The GATAtype transcription factors GNC and GNL/CGA1 repress gibberellin signaling downstream from DELLA proteins and PHYTOCHROME-INTERACTING FACTORS. Genes Dev. 24, 2093-2104. doi: 10.1101/gad.594910

Rodermel, S. (2001). Pathways of plastid-to-nucleus signaling. Trends Plant Sci. 6, 471-478. doi: 10.1016/S1360-1385(01)02085-4

Rodriguez-Concepcion, M., and Stange, C. (2013). Biosynthesis of carotenoids in carrot: an underground story comes to light. Arch. Biochem. Biophys. 539, 110-116. doi: 10.1016/j.abb.2013.07.009

Rodríguez-Villalón, A., Gas, E., and Rodríguez-Concepción, M. (2009). Phytoene synthase activity controls the biosynthesis of carotenoids and the supply of their metabolic precursors in dark-grown Arabidopsis seedlings. Plant J. 60, 424-435. doi: 10.1111/j.1365-313X.2009.03966.x

Rottet, S., Besagni, C., and Kessler, F. (2015). The role of plastoglobules in thylakoid lipid remodeling during plant development. Biochim. Biophys. Acta Bioenerget. 1847, 889-899. doi: 10.1016/j.bbabio.2015.02.002

Rottet, S., Devillers, J., Glauser, G., Douet, V., Besagni, C., and Kessler, F. (2016). Identification of plastoglobules as a site of carotenoid cleavage. Front. Plant Sci. 7:1855. doi: 10.3389/fpls.2016.01855

Ruiz-Sola, M. Á, and Rodríguez-Concepción, M. (2012). Carotenoid biosynthesis in Arabidopsis: a colorful pathway. Arabidopsis book 10:e0158. doi: 10.1199/tab. 0158

Sadali, N. M., Sowden, R. G., Ling, Q., and Jarvis, R. P. (2019). Differentiation of chromoplasts and other plastids in plants. Plant Cell Rep. 38, 803-818. doi: 10.1007/s00299-019-02420-2

Sagisaka, S. (2008). The proliferation of amyloplasts in meristematic cells of developing stolons of potato and apple callus: progenitors of proplastids. J. Plant Physiol. 165, 1678-1690. doi: 10.1016/j.jplph.2008.02.003

Saijo, Y., Sullivan, J. A., Wang, H., Yang, J., Shen, Y., Rubio, V., et al. (2003). The COP1-SPA1 interaction defines a critical step in phytochrome A-mediated regulation of HY5 activity. Genes Dev. 17, 2642-2647. doi: 10.1101/gad.1122903

Sakamoto, W., Miyagishima, S. Y., and Jarvis, P. (2008). Chloroplast biogenesis: control of plastid development, protein import, division and inheritance. The Arabidopsis book (American Society of Plant Biologists, Rockville) 6, e0110. doi: $10.1199 /$ tab.0110

Schweiggert, R. M., Steingass, C. B., Heller, A., Esquivel, P., and Carle, R. (2011). Characterization of chromoplasts and carotenoids of red-and yellow-fleshed papaya (Carica papaya L.). Planta 234, 1031-1044. doi: 10.1007/s00425-0111457-1

Scott, F. M., Bystrom, B. G., and Bowler, E. (1963). Persea americana, mesocarp cell structure, light and electron microscope study. Bot. Gaz. 124, 423-428. doi: $10.1086 / 336230$

Senser, M., Schötz, F., and Beck, E. (1975). Seasonal changes in structure and function of spruce chloroplasts. Planta 126, 1-10. doi: 10.1007/BF00389354
Ševćíková, T., Horák, A., Klimeš, V., Zbránková, V., Demir-Hilton, E., Sudek, S., et al. (2015). Updating algal evolutionary relationships through plastid genome sequencing: did alveolate plastids emerge through endosymbiosis of an ochrophyte? Sci. Rep. 5:10134. doi: 10.1038/srep10134

Shah, M., Soares, E. L., Lima, M. L., Pinheiro, C. B., Soares, A. A., Domont, G. B., et al. (2016). Deep proteome analysis of gerontoplasts from the inner integument of developing seeds of Jatropha curcas. J. Proteomics 143, 346-352. doi: 10.1016/j.jprot.2016.02.025

Singh, R., Singh, S., Parihar, P., Singh, V. P., and Prasad, S. M. (2015). Retrograde signaling between plastid and nucleus: a review. J. Plant Physiol. 181, 55-66. doi: 10.1016/j.jplph.2015.04.001

Sobieszczuk-Nowicka, E., Di Sandro, A., Del Duca, S., Serafini-Fracassini, D., and Legocka, J. (2007). Plastid-membrane-associated polyamines and thylakoid transglutaminases during etioplast-to-chloroplast transformation stimulated by kinetin. Physiol. Plant 130, 590-600. doi: 10.1111/j.1399-3054.2007.00 922.x

Solis-Badillo, E., Agama-Acevedo, E., Tiessen, A., Valenzuela, J. A. L., and BelloPerez, L. (2020). ADP-Glucose Pyrophosphorylase Is Located in the Plastid and Cytosol in the Pulp of Tropical Banana Fruit (Musa acuminata). Plant Foods Hum. Nutr. 75, 76-82. doi: 10.1007/s11130-019-00788-w

Solymosi, K., Martinez, K., Kristóf, Z., Sundqvist, C., and Böddi, B. (2004). Plastid differentiation and chlorophyll biosynthesis in different leaf layers of white cabbage (Brassica oleracea cv. capitata). Physiol. Plant. 121, 520-529. doi: 10. 1111/j.0031-9317.2004.00349.x

Solymosi, K., and Schoefs, B. (2010). Etioplast and etio-chloroplast formation under natural conditions: the dark side of chlorophyll biosynthesis in angiosperms. Photosynth. Res. 105, 143-166. doi: 10.1007/s11120-010-9568-2

Solymosi, K., Tuba, Z., and Böddi, B. (2013). Desiccoplast-etioplast-chloroplast transformation under rehydration of desiccated poikilochlorophyllous Xerophyta humilis leaves in the dark and upon subsequent illumination. J. Plant Physiol. 170, 583-590. doi: 10.1016/j.jplph.2012.11.022

Sperling, U., Franck, F., van Cleve, B., Frick, G., Apel, K., and Armstrong, G. A. (1998). Etioplast differentiation in Arabidopsis: both PORA and PORB restore the prolamellar body and photoactive protochlorophyllide-F655 to the cop1 photomorphogenic mutant. Plant Cell 10, 283-296. doi: 10.1105/tpc.10.2.283

Stephenson, P. G., Fankhauser, C., and Terry, M. J. (2009). PIF3 is a repressor of chloroplast development. Proc. Natl. Acad. Sci. U.S.A. 106, 7654-7659. doi: 10.1073/pnas.0811684106

Sun, T., and Li, L. (2020). Toward the 'golden'era: the status in uncovering the regulatory control of carotenoid accumulation in plants. Plant Sci. 290:110331. doi: 10.1016/j.plantsci.2019.110331

Sun, T., Yuan, H., Cao, H., Yazdani, M., Tadmor, Y., and Li, L. (2018). Carotenoid metabolism in plants: the role of plastids. Mol. Plant 11, 58-74. doi: 10.1016/j. molp.2017.09.010

Sun, T., Zhou, F., Huang, X.-Q., Chen, W.-C., Kong, M.-J., Zhou, C.-F., et al. (2019). ORANGE represses chloroplast biogenesis in etiolated Arabidopsis cotyledons via interaction with TCP14. Plant Cell 31, 2996-3014. doi: 10.1105/ tpc. 18.00290

Suzuki, T., Tsunekawa, S., Koizuka, C., Yamamoto, K., Imamura, J., Nakamura, K., et al. (2013). Development and disintegration of tapetum-specific lipidaccumulating organelles, elaioplasts and tapetosomes, in Arabidopsis thaliana and Brassica napus. Plant sci. 207, 25-36. doi: 10.1016/j.plantsci.2013.02.008

Tang, X., Miao, M., Niu, X., Zhang, D., Cao, X., Jin, X., et al. (2016). Ubiquitin-conjugated degradation of golden 2-like transcription factor is mediated by CUL 4-DDB 1-based E 3 ligase complex in tomato. New Phytol. 209, 1028-1039. doi: 10.1111/nph.13635

Tanios, S., Eyles, A., Tegg, R., and Wilson, C. (2018). Potato tuber greening: a review of predisposing factors, management and future challenges. Am. J. Potato Res. 95, 248-257. doi: 10.1007/s12230-018-9648-y

Tejos, R. I., Mercado, A. V., and Meisel, L. A. (2010). Analysis of chlorophyll fluorescence reveals stage specific patterns of chloroplast-containing cells during Arabidopsis embryogenesis. Biol. Res. 43, 99-111. doi: 10.4067/S071697602010000100012

Thomson, W., and Whatley, J. M. (1980). Development of nongreen plastids. Annu. Rev. Plant Physiol. 31, 375-394. doi: 10.1146/annurev.pp.31.060180. 002111

Toledo-Ortiz, G., Johansson, H., Lee, K. P., Bou-Torrent, J., Stewart, K., Steel, G., et al. (2014). The HY5-PIF regulatory module coordinates light 
and temperature control of photosynthetic gene transcription. PLoS Genet. 10:e1004416. doi: 10.1371/journal.pgen.1004416

Toyoshima, Y., Onda, Y., Shiina, T., and Nakahira, Y. (2005). Plastid transcription in higher plants. Crit. Rev. Plant Sci. 24, 59-81. doi: 10.1080/ 07352680590910438

Vigil, E., and Ruddat, M. (1985). Development and enzyme activity of protein bodies in proteinoplasts of tobacco root cells. Histochemistry 83, 17-27. doi: 10.1007/BF00495295

Wang, H., Ma, L. G., Li, J. M., Zhao, H. Y., and Deng, X. W. (2001). Direct interaction of Arabidopsis cryptochromes with COP1 in light control development. Science 294, 154-158. doi: 10.1126/science.1063630

Wang, P., Fouracre, J., Kelly, S., Karki, S., Gowik, U., Aubry, S., et al. (2013). Evolution of GOLDEN2-LIKE gene function in C 3 and C 4 plants. Planta 237, 481-495. doi: 10.1007/s00425-012-1754-3

Wang, X., Sun, F., Han, C., Chen, Q., Yang, X., Cheng, J., et al. (2020). The E-2hexenal play critical role in carotenoids activated inner membrane structures transformation in the chloroplasts. Authorea doi: 10.22541/au.158316318. 85083277

Waters, M. T., and Langdale, J. A. (2009). The making of a chloroplast. EMBO J. 28, 2861-2873. doi: 10.1038/emboj.2009.264

Wei, N., Kwok, S. F., von Arnim, A. G., Lee, A., McNellis, T. W., Piekos, B., et al. (1994). Arabidopsis COP8, COP10, and COP11 genes are involved in repression of photomorphogenic development in darkness. Plant Cell 6, 629-643. doi: 10.1105/tpc.6.5.629

Welsch, R., Zhou, X., Koschmieder, J., Schlossarek, T., Yuan, H., Sun, T., et al. (2020). Characterization of cauliflower OR mutant variants. Front. Plant Sci. 10:1716. doi: 10.3389/fpls.2019.01716

Welsch, R., Zhou, X., Yuan, H., Álvarez, D., Sun, T., Schlossarek, D., et al. (2018). Clp protease and OR directly control the proteostasis of phytoene synthase, the crucial enzyme for carotenoid biosynthesis in Arabidopsis. Mol. Plant 11, 149-162. doi: 10.1016/j.molp.2017.11.003

Whatley, J. M. (1978). A suggested cycle of plastid developmental interrelationships. New Phytol. 80, 489-502. doi: 10.1111/j.1469-8137. 1978.tb01581.x

Wicke, S., Schneeweiss, G. M., Depamphilis, C. W., Müller, K. F., and Quandt, D. (2011). The evolution of the plastid chromosome in land plants: gene content, gene order, gene function. Plant Mol. Biol. 76, 273-297.

Wise, R. R. (2007). "The diversity of plastid form and function," in The Structure and Function of Plastids, Vol. 23, eds R. R. Wise and J. K. Hoober (Dordrecht: Springer), 3-26. doi: 10.1007/978-1-4020-4061-0_1

Wrischer, M., and Devide, Z. (2002). Chromoplasts-the last stages in plastid development. Int. J. Dev. Biol. 35, 251-258.

Wurtzel, E. T., Cuttriss, A., and Vallabhaneni, R. (2012). Maize provitamin a carotenoids, current resources, and future metabolic engineering challenges. Front. Plant Sci. 3:29. doi: 10.3389/fpls.2012.00029

Xie, Y., Kang, R., Sun, X., Zhong, M., Huang, J., Klionsky, D. J., et al. (2015). Posttranslational modification of autophagy-related proteins in macroautophagy. Autophagy 11, 28-45. doi: 10.4161/15548627.2014. 984267

Yadav, D., Zemach, H., Belausov, E., and Charuvi, D. (2019). Initial proplastid-tochloroplast differentiation in the developing vegetative shoot apical meristem of Arabidopsis. Biochem. Biophys. Res. Commun. 519, 391-395. doi: 10.1016/j. bbrc.2019.09.019

Yang, J., Lin, R., Sullivan, J., Hoecker, U., Liu, B., Xu, L., et al. (2005). Light regulates COP1-mediated degradation of HFR1, a transcription factor essential for light signaling in Arabidopsis. Plant Cell 17, 804-821. doi: 10.1105/tpc.104.030205

Ye, X., Al-Babili, S., Klöti, A., Zhang, J., Lucca, P., Beyer, P., et al. (2000). Engineering the provitamin A ( $\beta$-carotene) biosynthetic pathway into (carotenoid-free) rice endosperm. Science 287, 303-305. doi: 10.1126/science. 287.5451.303

You, M. K., Lee, Y. J., Kim, J. K., Baek, S. A., Jeon, Y. A., Lim, S. H., et al. (2020). The organ-specific differential roles of rice DXS and DXR, the first two enzymes of the MEP pathway, in carotenoid metabolism in Oryza sativa leaves and seeds. BMC Plant Biol. 20:167. doi: 10.1186/s12870-020-02357-9

Zhang, C., Zhang, J., Tang, Y., Liu, K., Liu, Y., Tang, J., et al. (2020). DEEP GREEN PANICLE1 suppresses GOLDEN2-LIKE activity to reduce chlorophyll synthesis in rice glumes. Plant Physiol. 185, 469-477. doi: 10.1093/plphys/ kiaa038

Zhang, J., Hu, Z., Yao, Q., Guo, X., Nguyen, V., Li, F., et al. (2018). A tomato MADS-box protein, SICMB1, regulates ethylene biosynthesis and carotenoid accumulation during fruit ripening. Sci. Rep. 8, 1-15. doi: 10.1038/s41598-01717765-5

Zhang, M. K., Zhang, M. P., Mazourek, M., Tadmor, Y., and Li, L. (2014). Regulatory control of carotenoid accumulation in winter squash during storage. Planta 240, 1063-1074. doi: 10.1007/s00425-014-2147-6

Zhong, S., Zhao, M., Shi, T., Shi, H., An, F., Zhao, Q., et al. (2009). EIN3/EIL1 cooperate with PIF1 to prevent photo-oxidation and to promote greening of Arabidopsis seedlings. Proc. Natl. Acad. Sci. U.S.A. 106, 21431-21436. doi: 10. $1105 /$ tpc. 17.00508

Zhu, M., Lin, J., Ye, J., Wang, R., Yang, C., Gong, J., et al. (2018). A comprehensive proteomic analysis of elaioplasts from citrus fruits reveals insights into elaioplast biogenesis and function. Hortic. Res. 5, 1-11. doi: 10.1038/s41438017-0014-x

Conflict of Interest: The authors declare that the research was conducted in the absence of any commercial or financial relationships that could be construed as a potential conflict of interest.

Copyright (c) 2021 Choi, Yi and Ha. This is an open-access article distributed under the terms of the Creative Commons Attribution License (CC BY). The use, distribution or reproduction in other forums is permitted, provided the original author(s) and the copyright owner(s) are credited and that the original publication in this journal is cited, in accordance with accepted academic practice. No use, distribution or reproduction is permitted which does not comply with these terms. 